\title{
GAME COMO TEXTO COMO JOGO: A EXPERIÊNCIA COMUNICATIVA DOS JOGOS DIGITAIS
}

\author{
Carlos Magno Camargos Mendonça \& Filipe Alves de Freitas
}

\begin{abstract}
RESUMO
Propomos pensar o videogame como texto, mas sem entendê-lo literalmente como uma manifestação verbal, e sim reconhecendo que muitos pressupostos da teoria literária são relevantes à sua análise. Essa opção parece nos situar junto aos narratólogos, que exaltam os games como novas manifestações da narrativa, mas se apegam a uma concepção de texto como mundo que valoriza efeitos ilusionistas. Ao contrário, interessam-nos experiências que, na contramão dessa vertente, reconhecem a possibilidade de pensar o game como um texto que é um jogo-um objeto incompleto a ser atualizado pelo leitor em uma relação auto-reflexiva com os signos que o compõem, noção central a teorias como as de Iser e Dewey. A partir daí, podemos privilegiar, ao invés das estratégias de imersão dos grandes mundos virtuais, os pequenos jogos casuais independentes (como Small Worlds, Grey, The Beggar, e Dys4ia) analisando como neles se dão experiências que nos permitem reexaminar o potencial estético do meio.
\end{abstract}

\section{PALAVRAS-Chave}

Texto; experiência estética; imersão; performance

\section{INTRODUÇÃo}

"Há ruído demais", nos diz um letreiro. A cena pixelizada que se segue parece confirmar o enunciado: carece de nitidez e requer esforço para ser decifrada. Precisamos de alguns segundos para compreender que três quadrados coloridos sugerem a forma de uma pessoa em pé, no centro de um domo transparente, em um cenário sombrio.

Trata-se da cena inicial de Small Worlds, jogo enviado por David Shute para a sexta edição da Casual Gameplay Design Competition, que tinha como tema "exploração". O conceito da obra, a princípio, parece simples: usando as setas do teclado, o jogador controla um personagem em um cenário que vai se tornando visível conforme é percorrido. Um dos aspectos distintivos do jogo é o seu visual: ele parece evocar o estilo gráfico de baixa resolução dos primeiros games, construído com um número limitado de pixels. Poucas informações claras são dadas a respeito da narrativa de fundo e da ambientação: logo após o letreiro inicial o jogador é posto a explorar um cenário que pode ser um laboratório ou estação espacial em ruínas. Conforme explora novas áreas, o campo de visão se amplia, como se uma câmera virtual recuasse. Com isso, os "pixels" diminuem de tamanho na tela (e com eles o personagem), o que resulta em uma maior resolução — a relação entre o número de pixels e a área da tela — tornando o cenário gradualmente mais nítido (Figura 1). Na parte inferior do cenário podem ser encontrados quatro "portais" coloridos, objetos que, ao serem tocados pelo avatar, transportam-no a outros "mundos" (Figura 2), onde a mesma lógica de exploração gradual impera. 
Small Worlds venceu o prêmio do júri e foi escolhido pela audiência do site como o melhor jogo da competição, sendo ainda eleito o melhor jogo de 2009 pelos colaboradores de jayisgames.com. Na página do site dedicada a ele, usuários se divertem trocando interpretações a respeito da narrativa do jogo, mas é igualmente interessante discutir as estratégias de uso e diálogo com a matéria do meio. É inegável que gráficos pixelizados compõem um dos elementos essenciais dessa matéria, uma vez que remetem a um estilo típico dos games que chegou a ser apropriado pelas artes plásticas, sob a forma da chamada "Pixel Art". Com a difusão da tecnologia digital, o pixel - abreviação de Picture element (elemento da imagem) — tornou-se um componente básico da experiência contemporânea das mídias e converteu-se em unidade essencial de escala, o que se torna particularmente evidente em Small Worlds. Os "mundos pequenos" do jogo de Shute poderiam facilmente ocupar uma fração do tamanho de uma unha da área das telas dos aparelhos de alta definição mais recentes.

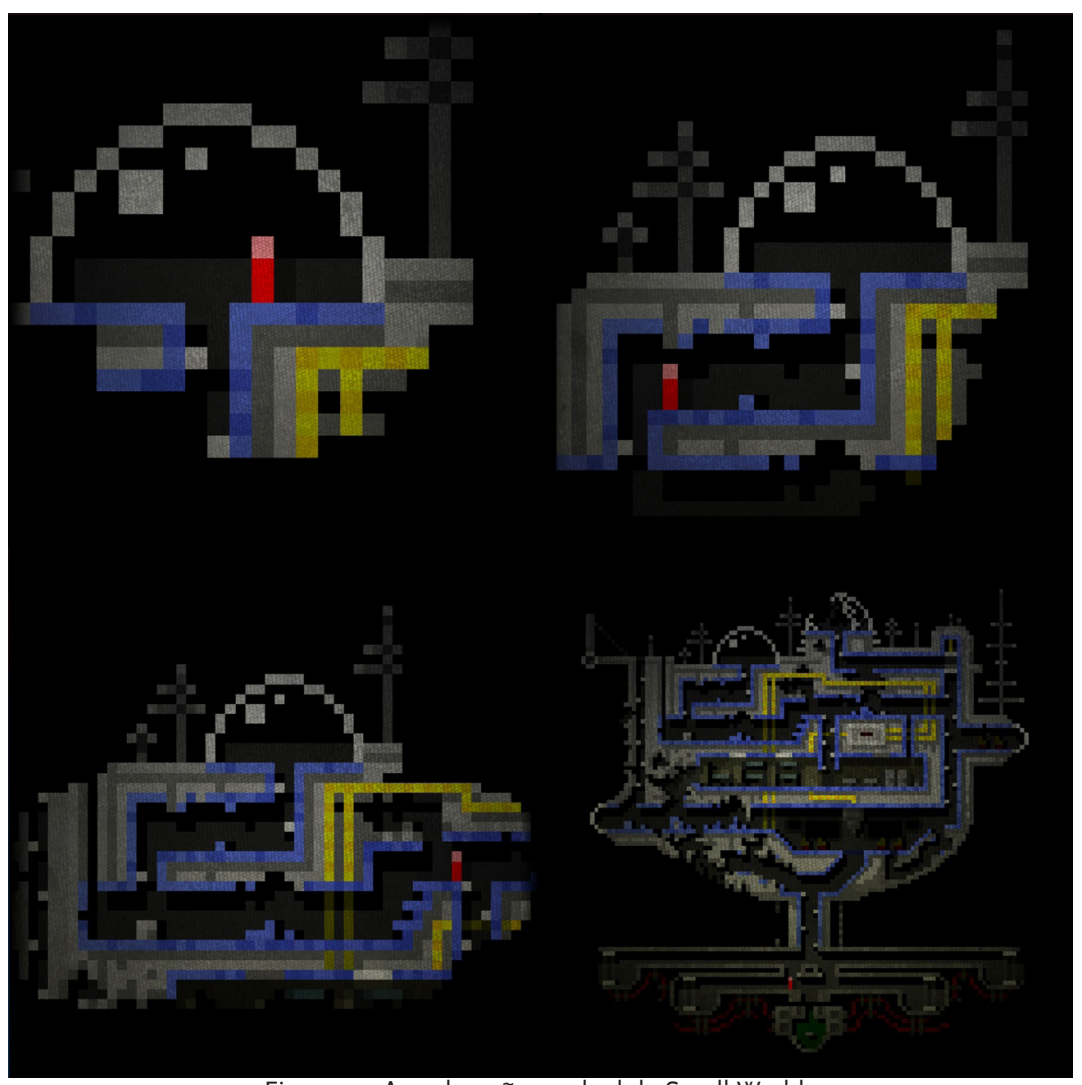

Figura 1 - A exploração gradual de Small Worlds

Talvez seja isso o que o autor sugere, ao iniciar o jogo com a frase "há ruído demais". Na "Era HD", o pixel tornou-se desvalorizado, uma vez que só pode ser usado em grande quantidade. $\mathrm{Na}$ indústria do video game, sua desvalorização começou ainda mais cedo: já na década de 1980 surgiram os primeiros jogos com gráficos vetoriais. $\mathrm{Na}$ imagem digital tradicional, também conhecida como gráfico raster, a tela era desenhada por varredura, em fileiras horizontais de pixels; no gráfico vetorial, desenha-se a imagem na tela como traços ligando pontos. Com a imagem vetorial, os gráficos de games ganharam mais nitidez, mas a arte dos jogos deixou de ser criada pixel por pixel. 
Essa tendência se fortaleceu com o surgimento da computação gráfica e suas imagens tridimensionais construídas por vértices e polígonos, reduzindo o pixel a uma mera limitação de hardware, a resolução do display de vídeo.

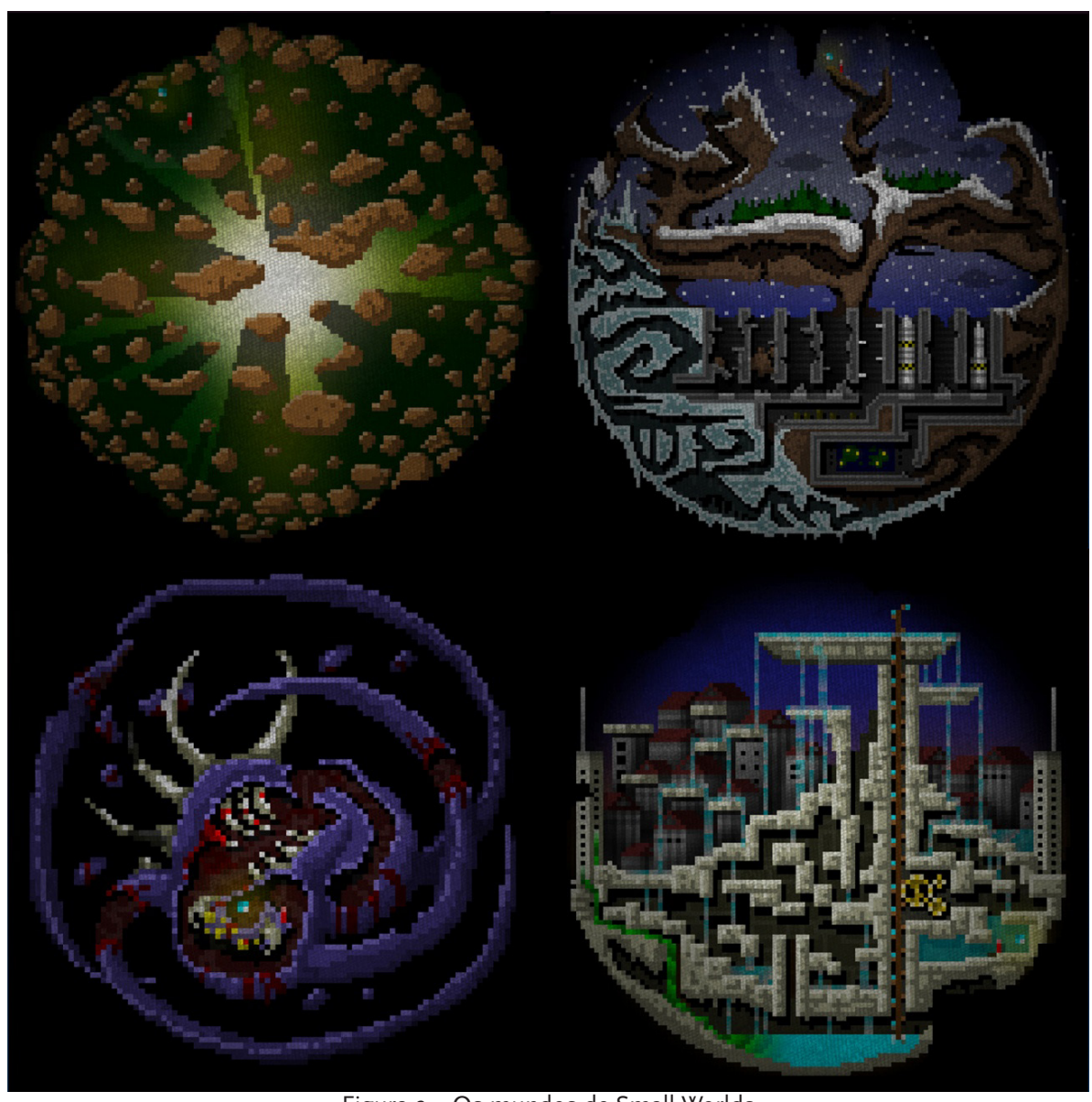

Figura 2 - Os mundos de Small Worlds

Small Worlds seria então uma ode aos gráficos raster das primeiras décadas da história do videogame, uma época mais "simples" em contraste com as imagens excessivamente complexas dos jogos mais recentes. Não se trata, no entanto, de mera nostalgia. O resgate dos gráficos de baixa resolução em Small Worlds não é apenas uma manifestação da saudade dos jogos que muitos dos adultos de hoje experimentaram na infância, mas sim uma retomada de um elemento importante da arte gráfica do video game: a limitação técnica.

A hipótese de que o artista encontra a sua inventividade ao confrontar limitações impostas pela matéria do meio em que cria é aventada por Luigi Pareyson (1997). Ele sugere que a criação artística opera como um "diálogo com a matéria", e disso deduz que a arte não consiste na aplicação bem sucedida de técnicas ou habilidades aprendidas, e sim em um processo histórico contínuo de invenção de modos de uso da matéria. Por isso, só poderíamos conceber a arte como "linguagem" de modo metafórico: enquanto que há artes que adotam a linguagem como matéria, como a poesia, há também outras, como a escultura e a arquitetura, que devem ser entendidas não como resultado da aplicação de um sistema organizado como o da língua e sim como fruto de uma atividade 
produtiva, um "tal fazer que, enquanto faz, inventa o por fazer e o modo de fazer" (Pareyson, 1997: 26). Assim, Pareyson concebe a atividade do artista como aquela em que uma "linguagem" não é dada a priori, mas desenvolvida durante a produção e a partir de possibilidades e resistências oferecidas pela matéria e só percebidas pelo artista em seu confronto com ela.

Pelo menos no que diz respeito ao aspecto gráfico, o videogame de hoje enfrenta poucos obstáculos. Ao trabalhar com baixas resoluções e imagens construídas pixel a pixel, Shute traz de volta ao videogame a Pixel Art, a arte de construir imagens usando blocos de cor pura. É a retomada de um obstáculo que havia sido superado pela tecnologia, para que ele possa voltar a ser superado pelo artista: como criar imagens convincentes com um número limitado de elementos quadrados?

A mecânica de Small Worlds serve para revalorizar as técnicas da Pixel Art. Trata-se de uma experiência do pixel diferente da que temos hoje nos aparelhos HD: ao invés de dedicar pouca atenção ao pixel individual, passando rapidamente por um fluxo de imagens de alta definição, somos forçados a explorar ergodicamente as imagens, descobrindo os cenários pixel a pixel, experimentando gradualmente o aumento de nitidez, com um olhar atento à habilidade necessária para construir essa nitidez com tão poucos elementos.

Small Worlds é apenas um entre muitos "pequenos jogos", obras de caráter independente e experimental, que desafiam as concepções sedimentadas na crítica especializada do meio. Para que possamos começar a compreender os efeitos que esses jogos produzem no jogador, sem ficarmos circunscritos somente ao forte senso de nostalgia que alguns deles evocam, devemos procurar entender o video game como um tipo de texto. Ao contrário de diversos autores do campo que procuraram fazer o mesmo - a maioria dos quais interessados nos possíveis usos dos games como ferramentas pedagógicas - , não propomos aqui entender os jogos literalmente como manifestações verbais. Essa decisão nos situa à parte da maioria dos estudos sobre o hipertexto ou o cibertexto - termo cunhado por Espen Aarseth (1997), autor que certamente se oporia ao uso metafórico e mais abrangente da noção de "texto" aqui proposta. Esses estudos, em geral, entendem "texto" como um veículo material que transmite verbalmente informações ou sentidos, e tratam o game como um tipo especial de texto, privilegiando as particularidades que os distinguem de outras formas textuais.

Em vez disso, usamos "texto" em um sentido frouxo, menos como um conceito formal que como um ponto de partida para advogar que muitos pressupostos da teoria literária podem ser aplicados à sua análise. No campo de estudos sobre o tema, os narratólogos, que exaltam os jogos digitais como novas manifestações dos fenômenos narrativos, fazem algo similar, e essa opção parece nos situar junto a eles. Não é bem o caso, como tentaremos demonstrar.

\section{QUEBRANDO A IMERSÃo}

Em geral, os narratólogos parecem operar, em suas análises, a partir da metáfora do "texto como mundo". Concebem video games como realidades virtuais, tomando o 
termo "virtual" no sentido de "falso" ou "duplo", em que carrega uma afinidade com o conceito de ficção, e se interessam pelas estratégias através das quais o texto/game produz esse mundo na imaginação do leitor/jogador. Assim, tendem a privilegiar efeitos como o da imersão, via de regra tomada como a experiência intensa de presença diante do mundo virtual produzida através das possibilidades de interação com o ambiente ficcional e de uma representação visualmente convincente. A imersão pressupõe, então, um realismo de tipo ilusionista.

Essa valorização dos efeitos realistas nos ambientes virtuais é nítida no pensamento de Janet Murray (2003), a representante mais famosa dessa vertente. Murray é a propositora do conceito de "ciberdrama", uma concepção de narrativa emergente e interativa que só é plenamente realizável através da tecnologia ficcional do holodeck um ambiente imersivo povoado por hologramas sólidos inteligentes, e que só existe no universo futurístico da série de TV Star Trek.

Esse fetichismo da tecnologia ilusionista é prejudicial ao estudo dos efeitos estéticos dos video games, uma vez que pode nos induzir a pensar, como Castañares (2007), que a realidade virtual visa retomar um objetivo que a arte havia perseguido até o século XX, e desde então abandonado: o de criar ilusões. Diz ele: "a novidade dessas novas representações é que pretendem e, algumas de suas manifestações conseguem, experiências que são semelhantes às da percepção da realidade e não à interpretação das representações."1 (Castañares, 2007: 42).

Para a narratóloga Marie-Laure Ryan (2001), o realismo ilusionista de que depende a imersão em um "mundo do texto" de fato parece incompatível com o exercício das faculdades críticas. "Para que um leitor seja capturado em uma história", nota ela, "o mundo textual deve ser acessível através de concentração sem esforço"2 (Ryan, 2001: 96), o que poderia ser equiparado a uma espécie de "cegueira semiótica", uma vez que o mundo representado é percebido em tal intensidade que não se vê os signos que o constroem.O problema, explica ela, é que atenção aos artifícios retóricos pelos quais um mundo emerge do texto é um aspecto essencial da apreciação estética e um dos efeitos favoritos da teoria literária pós-moderna. Ainda assim, uma vez que nenhum texto é inteiramente ilusionista, ela defende que seria possível haver imersão e, ao mesmo tempo, admirar a virtuosidade estilística que produz o efeito de presença.

Trata-se, no entanto, de uma estratégia argumentativa curiosa por parte de Ryan. Não podemos deixar de notar que a noção de que o principal efeito estético do game adviria de um reconhecimento das habilidades técnicas envolvidas na criação da obra remete ao conceito clássico de arte, tal como compreendido pelos gregos: techné, o conhecimento prático para manufaturar objetos (uma casa, estátua ou navio), ou efetuar uma tarefa (como comandar exércitos ou persuadir uma audiência), e que deu origem à expressão medieval ars, a partir do Renascimento usada para tratar da habilidade na produção da beleza (Tatarkiewicz, 1997: 39; 51). Ainda que essa concepção de arte permaneça presente

\footnotetext{
' Tradução livre dos autores.

${ }^{2}$ Tradução livre dos autores.
} 
no uso comum do termo, ela tem sido desafiada desde as vanguardas modernistas. Ao invés de calar críticos como Castañares, seu argumento parece confirmar a tese de que teríamos nos games e realidades virtuais uma espécie de atavismo estético.

A persistência de autores como Ryan e de grande parte dos teóricos e profissionais da indústria dos games em tratar o potencial estético dos games a partir de uma visão clássica da arte talvez tenha algo a ver com a resistência dos críticos e curadores contemporâneos em aceitar o video game como modalidade artística. Por isso, interessam-nos aquelas experiências que, na contramão dessa vertente da indústria e da academia, reconhecem a possibilidade de pensar o game como um texto que é um jogo - um texto que é um objeto incompleto a ser atualizado pelo leitor em uma relação de caráter auto-reflexivo com os signos que o compõem, noção central a teorias como as de Wolfgang Iser e John Dewey, e que nos permitem visualizar um processo comunicativo no qual não há um código comum dado a priori. A partir dessa angulação teórica, podemos deixar de lado a preocupação usual com as estratégias de imersão dos grandes mundos virtuais e voltarmos a nossa atenção para os pequenos jogos casuais independentes, analisando o modo como em quatro desses games - Small Worlds, Grey, The Beggar, e Dys4ia - se dão experiências comunicativas que nos permitem reexaminar o potencial estético desse novo meio.

\section{ROMPENDO O FLUXO DA EXPERIÊNCIA COTIDIANA}

Em Grey, de Kevin McGrath, o jogador assume o controle do que parece ser um garoto - na verdade, apenas uma silhueta estilizada formada por dois retângulos pretos (cabeça e tronco), dois retângulos brancos (os olhos), e dois traços (as pernas). No princípio do jogo o garoto se encontra no topo de uma plataforma, acompanhado por uma garota - uma silhueta semelhante à do protagonista, exceto pelos cabelos compridos. A garota fica imóvel, sentada na plataforma, olhando para o nada, enquanto o rapaz tenta chamar a sua atenção, sem sucesso. A partir daí o jogador assume o controle, e pode usar as setas do teclado para mover o personagem através do cenário.

Grey segue algumas das convenções do gênero "plataforma", caracterizado em geral por um cenário bi-dimensional, no qual o jogador deve levar o seu avatar a saltar entre plataformas para alcançar um determinado objetivo. No clássico Donkey Kong (Nintendo, 1981), o jogador controlava o Jumpman (mais tarde batizado de Mario), que devia saltar os barris jogados por um gorila para resgatar Pauline, sua namorada feita refém pelo vilão. Muitos dos jogos do gênero seguem um tipo de narrativa que remete aos romances de cavalaria medievais, nos quais o herói deve resgatar a donzela, derrotar um monstro ou trazer um tesouro para ganhar o coração da mocinha. A princípio, esse parece ser o caso de Grey, quando surgem setas coloridas que apontam em direção a objetos espalhados pelo cenário, que podem ser recolhidos pelo jogador e levados até a garota da plataforma (Figura 3). São sete objetos cujas cores correspondem às das setas que apontam para eles: um balão vermelho, um trevo verde, um colar azul, um pirulito roxo, um laço rosa, um ursinho de pelúcia alaranjado, e uma flor amarela. Podemos 
reconhecer nesses objetos presentes que um garoto daria a uma garota, de modo que é fácil presumir que o protagonista de Grey deve tentar conquistar a afeição de sua amada.

Contrariando as expectativas dos narratólogos, o jogo evidentemente não almeja um estilo gráfico realista. O cenário estilizado inclui árvores, casas e prédios, agrupados em seções que se assemelham ora a paisagens urbanas, ora a rurais, mas organizadas em plataformas, trechos do terreno que parecem flutuar no ar uns sobre os outros. Isso pode parecer estranho a um jogador não familiarizado com o gênero, mas trata-se de uma convenção dos jogos de plataforma. Outra "ruptura" em relação a um suposto ilusionismo reside no fato de que o cenário do jogo é apresentado em tons de cinza - daí o nome, que significa "cinza" em inglês. Os únicos elementos coloridos, a princípio, são as setas e os objetos para os quais apontam. Assim que o jogador leva um objeto até a garota da plataforma, a cor do objeto surge no cenário: plantas se tornam verdes quando o trevo é entregue, tijolos ficam vermelhos após o balão ser levado até a menina, e assim em diante (Figura 4). O cenário gradualmente se colore, e também ganha movimento e vida com o surgimento de pássaros, borboletas e peixes.

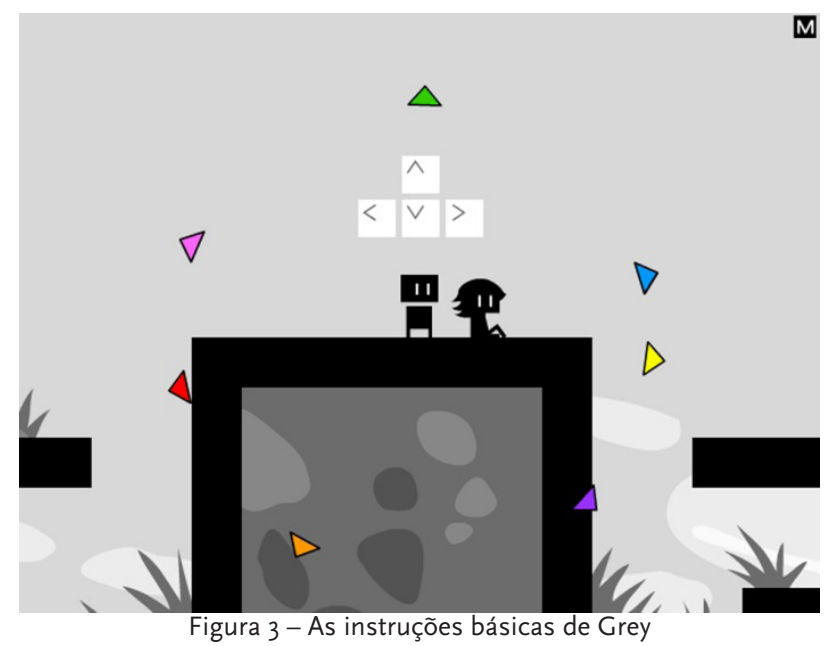

Uma análise guiada pelo viés narratológico poderia ver nessas quebras com um projeto ilusionista sinal de incompetência dos realizadores ou de uma adesão a um "modismo" estético, o de conferir destaque aos signos que compõem a obra em detrimento do efeito imersivo. Autores como Dewey (2010), no entanto, permitem que vejamos esse tipo de "ruptura" como o gatilho que dá início à experiência estética, que ele destaca como "uma" experiência capaz de promover o arrebatamento da criatura viva do fluxo contínuo de experiências cotidianas, graças a uma série de traços particulares: uma ruptura instauradora, um desenvolvimento organizado, um elemento unificador e uma possibilidade de "consumação". Na concepção deweyana, de influência darwinista, esses traços estão interrelacionados: pressupondo que, na natureza, a forma é resultado de uma estabilidade, Dewey sugere que o organismo busca sempre transformar a perturbação e o conflito em relações estáveis, o que resulta em uma consumação que tem caráter estético (Dewey, 2010: 77). Em outras palavras, na estrutura da experiência estética deweyana temos uma situação em que o organismo se depara com uma ruptura 
perceptual, se engaja com os elementos da experiência interessado em sanar essa ruptura, convoca elementos de seu próprio repertório a fim re reorganizar esses elementos e descobrir possíveis novas relações harmoniosas entre eles e, assim, resolve o conflito e atinge uma consumação estética.

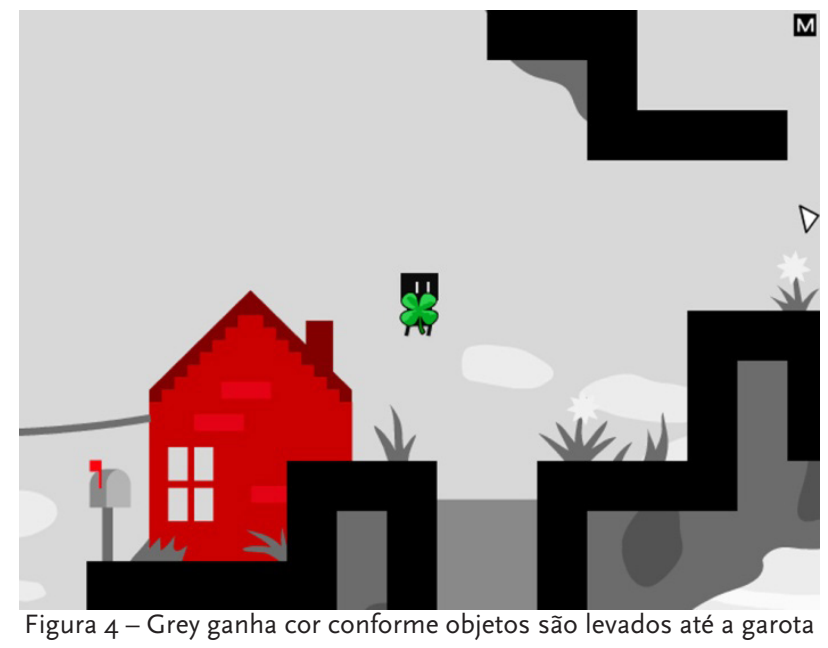

Em Grey, a ruptura com a qual o jogador se depara não é apenas visual. O jogo também "rompe" aos poucos com a interpretação inicial da sua narrativa de fundo. A cada vez que o jogador entrega com sucesso um objeto para a garota, seu avatar se torna um pouco mais transparente e difuso, sendo pouco mais que uma sombra durante a busca pelos últimos itens (Figura 5). Além disso, um dos itens traz um indício perturbador do que virá a seguir: a flor amarela encontra-se depositada, numa das seções mais distantes do cenário, diante de uma lápide (Figura 6). Quando o último objeto é entregue à garota, duas coisas ocorrem: o avatar do jogador desaparece, como se evaporasse no ar, e a garota pega nos braços um pássaro branco, possivelmente uma pomba, e a solta.

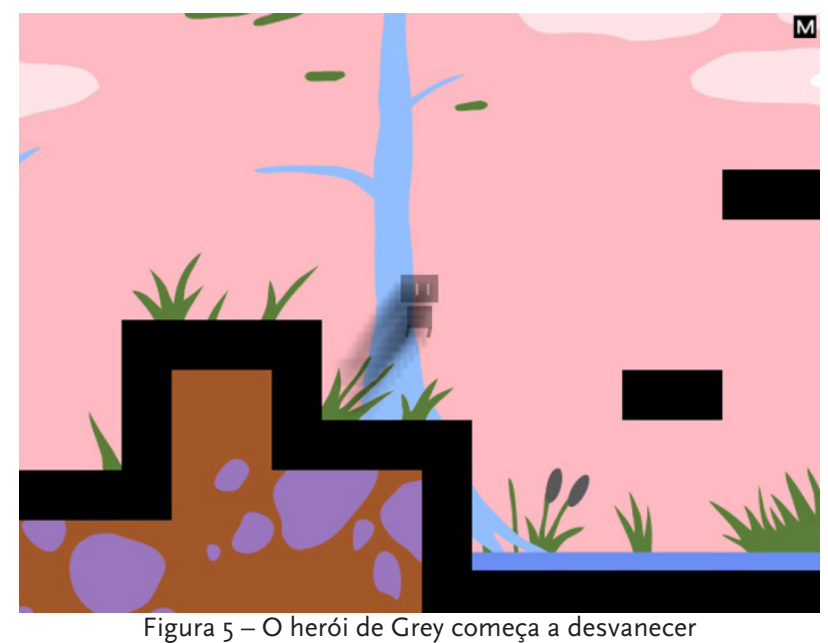




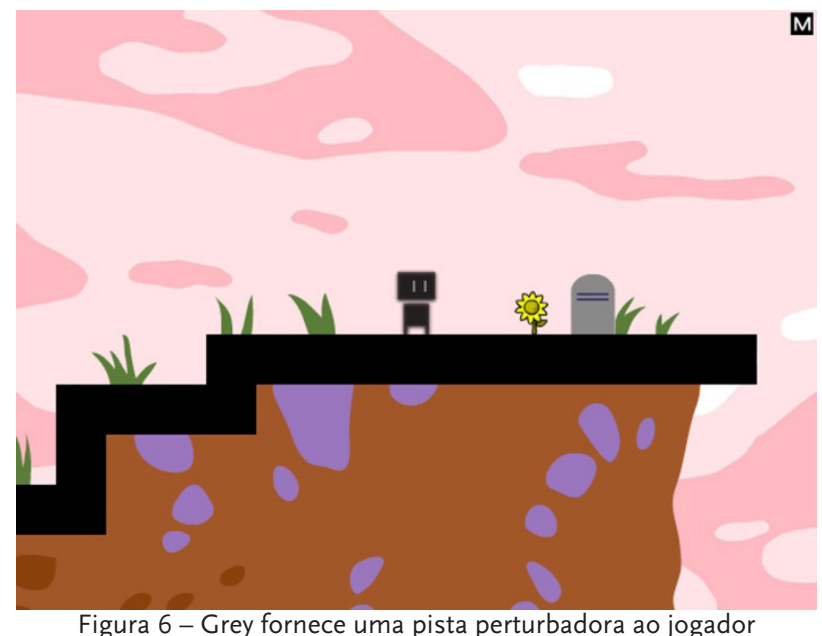

Assim, após conduzir a expectativa do jogador em uma direção, Grey a inverte: o protagonista não é mais um rapaz tentando conquistar sua amada, ele é um fantasma ou uma memória, e a garota, que pode ser sua namorada, esposa, mãe ou filha, é alguém que perdeu seu ente querido. O jogo não é mais um romance de cavalaria convertido em game de plataforma, mas uma narrativa sobre perda e superação do luto.

Isso não pressupõe, entretanto, uma concepção da obra como algo que carrega um "sentido oculto", como uma charada a ser solucionada. Ao contrário de Aarseth, que se ocupa da descrição da organização mecânica do texto como um veículo para o sentido, Iser (1994) entende que o sentido não é algo transmitido de um emissor a um receptor, mas sim "o produto de uma interação entre os sinais textuais e os atos de compreensão do leitor" (Iser, 1994: 9). Segundo ele, que propõe uma explicação compatível com a teoria de Dewey, os processos comunicativos literários envolvem um tipo de comunicação na qual não há um código comum a priori entre interlocutores, e esse código emergiria no decorrer do processo: caberia ao leitor descobrir o código subjacente a cada texto.

Para sermos mais exatos, podemos dizer que, nos termos de Iser, o texto tem dois "códigos". O "primeiro código", que consiste nas estruturas convencionais e bem estabelecidas do texto, tem como função fornecer ao leitor direções para que seja decifrado um "segundo código". É principalmente dessa atividade de deciframento que o leitor deriva prazer estético. As estratégias textuais conduzem o leitor nesse processo, operando de dois modos: pela seleção e pela combinação.

Através da seleção de uma ou mais convenções cria-se um sistema primeiro plano/ plano de fundo; o plano de fundo é o sistema do qual a norma foi extraída, e o primeiro plano, a norma extraída do contexto e dotada de novas significações. No texto literário, esse plano de fundo é o repertório, que é variável, pois não é dado e sim presumido pelo texto, e a relação primeiro plano/plano de fundo na qual ele se insere é dialética, pois o elemento familiar tem seu significado reestruturado pelo não-familiar.

Já a combinação dos elementos destacados pelo texto do repertório é o que produz novas significações. A seleção é uma conexão externa; a combinação, interna. Embora essa combinação seja feita pelo autor, o sentido só emerge da síntese efetuada pelo 
próprio leitor. O deciframento do "segundo código", então, consiste em o leitor buscar a "coerência" na correlação entre os signos, estabelecida pelo autor nos processos de seleção e combinação. A cada agrupamento de signos produzido nesse processo Iser dá o nome de Gestalt, que ele considera como o noema perceptivo do texto.

A ruptura inaugural (Dewey), ou a discrepância entre os códigos do autor e do leitor (Iser), pode ser interpretada de acordo com o pensamento de Pareyson como originada no diálogo do artista com a matéria da obra. Em Small Worlds essa ruptura pode ser identificada nos aspectos gráficos dos jogos, mas isso não quer dizer que a matéria dos games se limite à imagem. Elementos como regras e objetivos, assim como as ficções e narrativas que codificam essas regras e objetivos, podem ser incluídos como parte da matéria do video game. É preciso destacar que são elementos com um forte caráter convencional: mecânicas de jogo frequentemente se repetem, configurando gêneros de jogos, e a familiaridade que decorre da repetição tanto das mecânicas quanto dos temas narrativos e elementos ficcionais permite que o jogador aprenda como jogar com facilidade. "Romper" com essas convenções é também romper com a expectativa do jogador.

No caso de Grey, pode-se argumentar que se trata de uma narrativa pueril e de uma inversão que já foi transformada em clichê pelo cinema hollywoodiano, a de revelar ao final da obra que o herói não passava de um espírito. Mesmo assim, há de se perceber que Grey realiza o que Iser define como um caráter da experiência estética literária: o desvio de uma expectativa do leitor, que o conduz a se engajar ativamente com os elementos da obra a fim de restaurar a coerência entre eles. As convenções do gênero "plataforma", com sua mecânica e seus temas típicos, configuram um horizonte de expectativas inicial que conduz a uma interpretação, mas é desviado aos poucos pelo jogo. As "rupturas" apresentadas desafiam a primeira leitura, levando o jogador a refletir sobre os aspectos da mecânica e da narrativa do jogo, buscando reagrupá-los em uma nova organização que faça sentido. Assim, o sentido é construído pelo jogador durante o jogar, a partir de elementos e estratégias de condução apresentadas pelo jogo.

\section{ENCONTRANDO SENTIDO NAS REGRAS DO JOGO}

No caso de Small Worlds, é notável a maneira como o sentido é construído a partir da correlação interna entre os elementos da obra, cuja coerência deve ser sintetizada pelo leitor, reconhecendo a lógica por trás das seleções e combinações, conforme apontou Iser. No nível diegético, o jogador tem acesso gradual a algumas informações. Seu avatar encontra-se em uma espécie de estação espacial, destruída e deserta, e a partir dessa estação ele pode acessar quatro outros cenários (Figura 2): um campo de asteróides, talvez detritos da explosão de um corpo maior; um ambiente ártico com um bunker militar subterrâneo abandonado, onde se vê um mapa com vários pontos a piscar e dois mísseis restantes entre vários silos desocupados; uma cidade vazia tomada pela água e o esgoto, que jorram desordenadamente pelas estruturas; e uma caverna que mais se assemelha às entranhas em putrefação de uma gigantesca criatura morta, com estruturas que parecem ossos e costelas. Nesses quatro cenários o jogador deve encontrar um 
item, possivelmente uma fonte de energia que ele poderá usar para ativar a cápsula ou nave de fuga, e finalmente escapar da estação espacial abandonada. A partir da combinação desses elementos, que só podem ser reconhecidos em relação a um repertório construído a partir de filmes ou jogos de ficção científica, o jogador poderá formular uma imagem da narrativa de fundo de Small Worlds: talvez o herói seja o último sobrevivente de um devastador conflito nuclear, possivelmente desencadeado pela ameaça de um monstro gigante. Tomada em correlação com a mecânica de exploração gradual do jogo e seu estilo visual pixelizado, seleções que remetem aos gráficos raster e aos jogos das primeiras décadas do video game, podemos ainda ler o jogo como uma homenagem e um lamento nostálgico pelos jogos daquela era, seus temas fantásticos e seus cenários cuidadosamente construídos pixel a pixel.

Em Grey, o jogador é levado a construir a narrativa do jogo de uma maneira similar. $O$ autor selecionou, por exemplo, os sete objetos que o jogador deve encontrar (balão, trevo, flor, urso, colar, laço e pirulito) de maneira a criar uma relação primeiro plano/ plano de fundo com um repertório estabelecido, segundo a qual os itens são percebidos como signos de uma relação de amor ou afeto entre um homem/garoto e uma mulher/ garota. A escolha pela mecânica e o esquema de comandos dos jogos de plataforma também não é casual, mas opera a partir da presunção de um repertório de jogos que remetem a temas de resgate ou conquista de princesas para conduzir o jogador a uma leitura inicial que será invertida. A partir a inclusão de novos elementos (a transparência do protagonista, a lápide e o desaparecimento do avatar ao final), a coerência inicial é colocada em cheque e o jogador é forçado a buscar uma nova correlação coerente.

Outro jogo em que esse sistema é evidente, ainda que com um tipo diferente de resultado, é The Beggar, de Scott Brodie. Aqui o jogador controla um retângulo amarelo com olhos, em trajes castanhos: um mendigo maltrapilho em um mundo povoado por criaturas similares em trajes coloridos. É também um jogo bidimensional de plataforma, no qual o jogador pode mover o avatar para a direita ou esquerda usando as setas do teclado, pode pedir esmolas com a seta para baixo, comprar objetos com a seta para cima, e pegá-los usando a tecla "Z". "Pedir esmolas" significa, no caso, emanar um círculo translúcido amarelo que, ao tocar outros personagens, pode fazê-los produzir pequenos quadrados amarelos, as moedas do jogo (Figura 7).

Com o tempo, o protagonista vai se tornando gradualmente transparente, até o ponto em que aparece um "balão de pensamento", à maneira das histórias em quadrinhos, com o desenho de um peixe ou um pedaço de pão (Figura 8); é preciso recolher um dos dois objetos (usando "Z") para voltar ao normal. O mendigo precisa, portanto se alimentar, pois conforme se esvai também se torna mais lento, e ao desaparecer completamente o jogo termina. Há duas maneiras de nutrir o protagonista. Peixes podem ser obtidos de graça com o pescador idoso na extremidade esquerda do cenário. $O$ pescador, no entanto, irá desaparecer após certo tempo. Já o pão só pode ser comprado em uma tenda, e o seu preço aumenta a cada vez que é adquirido. 


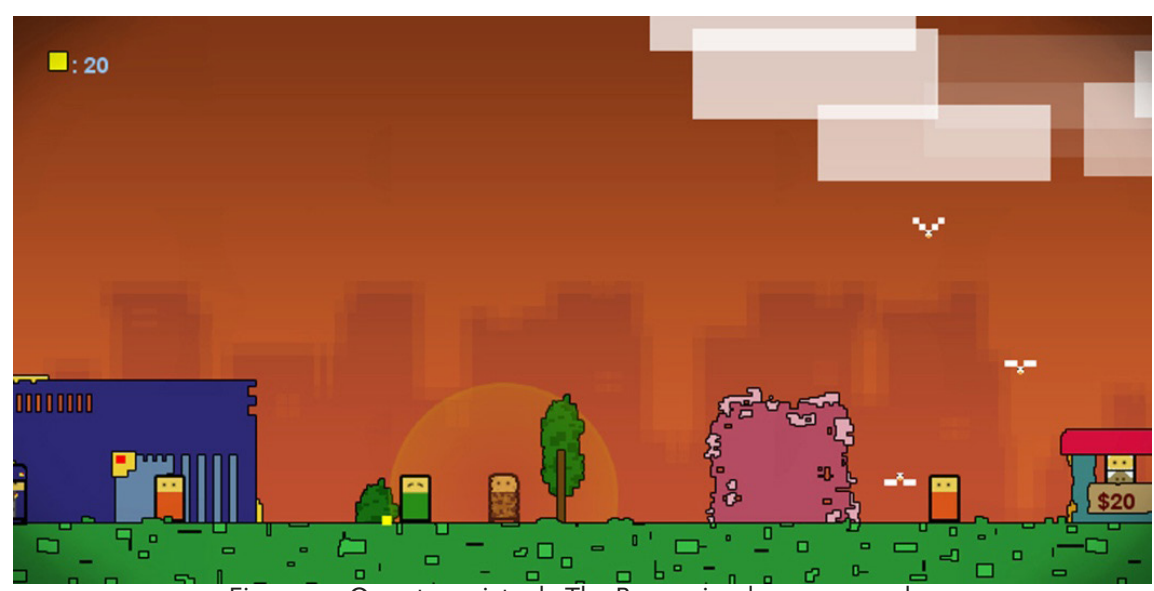

Figura 7 - O protagonista de The Beggar implora por moedas

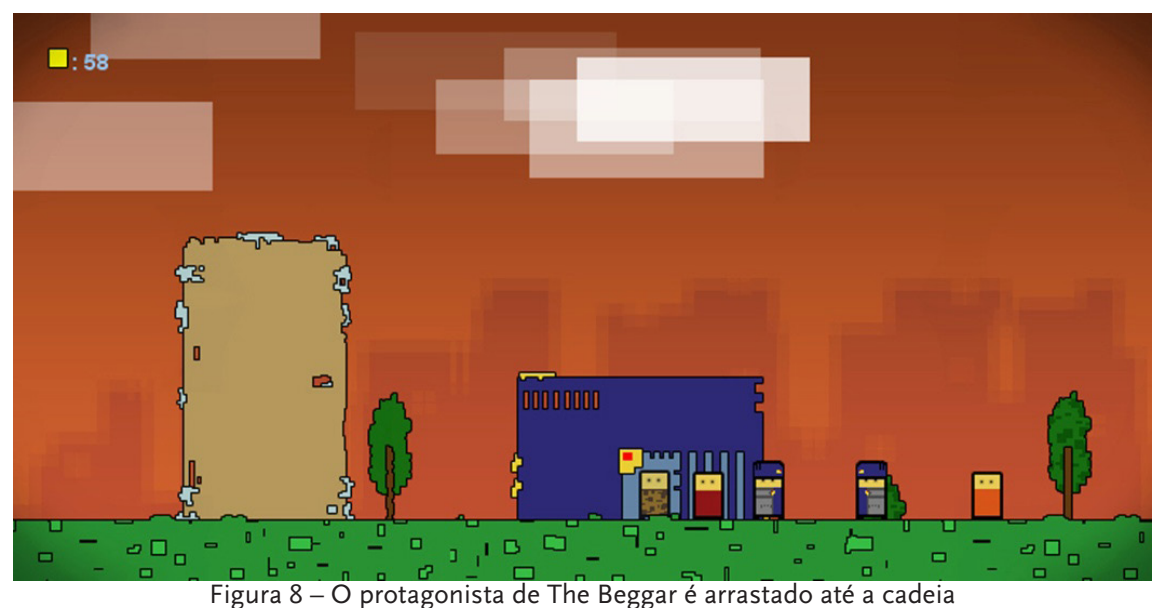

Além do mendigo, do pescador e do padeiro, há também os guardas: são personagens uniformizados que podem "prender" o mendigo caso ele use o círculo amarelo em sua proximidade. Prender, aqui, equivale a arrastar o avatar até a "delegacia" (um prédio azul com grades), e multá-lo recolhendo parte das suas economias. Os demais personagens são de três tipos: os de roupa verde tendem a doar moedas com mais facilidade, enquanto que os alaranjados e vermelhos costumam reagir mal aos pedidos. Eles emanam um círculo vermelho, e caso haja um policial no raio desse círculo, ele virá prender o pedinte. Caso o jogador implore repetidamente para o mesmo personagem, ele pode se transformar de verde para laranja, e daí para vermelho.

No início do jogo o mendigo é expulso da metade direita do cenário, que aparenta ser a seção mais abastada da cidade. Ele só poderá cruzar essa barreira caso consiga juntar duzentas moedas. Nessa parte do cenário ele pode continuar a pedir esmolas, comprar um balão em outra tenda e trocá-lo pelo cetro do rei, que reside na extremidade direita do cenário; nesse caso, rei e mendigo trocam de papéis. Como rei, o jogador pode usar o comando de implorar, mas com um efeito diferente, funcionando como uma ordem para que os policiais ao alcance prendam o personagem mais próximo. A "farsa", no entanto, é temporária, e logo o avatar volta à sua aparência original. 
Há três finais possíveis: o mendigo desaparece, esvaindo-se de fome; o mendigo senta-se no barco do pescador (o que pode ser lido como uma decisão de abandonar a cidade, ou mesmo de tornar-se um pescador como o velho); e o mendigo, travestido de rei, senta-se no trono. Não iremos nos concentrar nas possíveis interpretações desses finais, não só porque são abertos como também porque ocorrem de modo abrupto, sem que o jogo sinalize em direção a eles ou os construa como um objetivo. Mais interessante que eles é o sistema ou a lógica do mundo ficcional que Brodie arquiteta no jogo, e as conclusões a que esse sistema nos permite chegar.

O mundo de The Beggar é construído, como em Small Worlds e Grey, a partir da combinação entre elementos narrativos e aspectos de jogo. Uma das diferenças é que aqui muitos dos elementos narrativos (temas, cenários e personagens) não são extraídos de gêneros narrativos preexistentes, mas da realidade social urbana de hoje. A questão da mendicância é então apresentada a partir de mecânicas de jogo que incluem os cenários bidimensionais, o esquema de movimentação e a lógica de coleta de moedas típicos dos jogos de plataforma, assim como o sistema de compra de itens que normalmente encontramos no gênero do RPG. Outra diferença, talvez mais importante, é que a combinação aqui não tem como resultado a geração de uma narrativa ou de uma interpretação para a narrativa, e sim a criação de uma simulação estilizada e a correlação desse sistema com uma situação real, o que nos conduz a descobertas sobre essa situação a partir dos resultados que emergem da simulação.

A "lição" de The Beggar só pode ser aprendida jogando, conforme o jogador desenvolve estratégias mais eficientes para cumprir o objetivo proposto na introdução do jogo: reunir as duzentas moedas para acessar a parte "rica" da cidade. Após algumas sessões, pode-se logo perceber que o objetivo só pode ser atingido caso o jogador aja rapidamente e consiga acumular as moedas evadindo os guardas. Basta ser preso uma ou duas vezes, e a situação se deteriora a ponto de a recuperação se tornar impossível. O dinheiro perdido nas "multas" não pode ser readquirido, porque os transeuntes já não são mais caridosos devido aos pedidos insistentes; conforme o pão aumenta de preço torna-se um desafio simplesmente manter o protagonista vivo, dificultando enormemente o acúmulo de economias; e uma vez que a maioria dos personagens se irrita com os pedidos e começa a clamar pela prisão do mendigo, este passa a perder mais e mais moedas nas multas. No sistema criado por Brodie, quanto mais tempo o jogador joga, menor é a chance de ele conseguir realizar o objetivo, e o mendigo apenas afunda mais e mais, inexoravelmente, na miséria.

Assim, como nos outros jogos já citados, o sentido em The Beggar é produzido pelo jogador, a partir das condições fornecidas pelo jogo, mas aqui o sentido emerge do sistema dinâmico constituído pelas regras e objetivos do jogo como a interpretação do resultado de uma simulação - ainda que uma simulação simplificada e tendenciosa. É preciso que o jogador recomece o jogo do início diversas vezes para que fique clara a injustiça do sistema, que tende a agravar a pobreza do protagonista. Esse, como os outros jogos, demonstram que elementos de jogo - parâmetros, regras e ações possíveis - podem se tornar a matéria de uma relação comunicativa aos moldes daquela 
descrita por Pareyson, onde o código é reinventado e precisa ser decifrado a cada obra. Ao contrário do que defendem alguns opositores do reconhecimento do potencial estético dos games, para quem os aspectos de jogo são obstáculos à expressividade, temos aqui casos em que o sentido só pode ser decifrado a partir do próprio ato de jogar.

\section{DESCOBRINDO OS EFEITOS ESTÉTICOS DA PERFORMANCE DO JOGADOR}

Jogar um jogo digital pode parecer, ao leitor menos atento, uma realização por si só da estrutura da experiência estética proposta por Dewey: há um conflito que precisa ser resolvido pela intervenção do jogador; ele se interessa pelos elementos do jogo como condições de resolução desse conflito; e ele resgata elementos de experiências anteriores a fim de articular os elementos de jogo e desenvolver estratégias para sanar a ruptura. Com o auxílio de Pareyson e Iser, no entanto, podemos perceber que o conflito a que Dewey se refere não é uma situação problemática na narrativa, e sim um desvio do próprio código, e que esse desvio não pode ser resolvido através das ações mecânicas típicas de muitos jogos. Ao invés de reflexos, a experiência estética requer reflexão; e talvez um dos questionamentos mais válidos em relação à possibilidade de o videogame levar a esse tipo de experiência seja a noção de que a interação física própria do meio se coloque no caminho dessa atividade reflexiva.

A partir da noção de performance, no entanto, é possível conceber o modo como uma ação pode vir acompanhada de reflexão e ter significados ou efeitos sensíveis. De acordo com Schechner (2006), há três significados básicos para a palavra "performance". No uso comum, o termo equivale a "desempenho" e se refere ao sucesso ou eficiência na execução de uma tarefa, seja ela de caráter profissional, técnico, artístico ou até sexual. No campo da arte descreve uma modalidade artística específica, a da performance art. Num terceiro sentido, a performance pode ser vista como uma lente metodológica que permite analisar eventos enquanto performances. É nessa terceira acepção que podemos aplicar a noção à atuação do jogador.

Para Schechner, um dos principais aspectos do conceito de performance é o seu caráter de comportamento restaurado. Sejam performances de arte, rituais ou da vida cotidiana, elas são sempre ações físicas que não ocorrem pela primeira vez, ou seja, que são preparadas ou ensaiadas. Nos termos de Goffmann (citado por Schechner, 2006: 28-30), são ações que seguem um padrão pré-estabelecido que ele chama de "rotina", e que pode ser uma convenção social, um roteiro de teatro, ou até mesmo as regras de um jogo. Há comportamento restaurado mesmo quando o ator não tem consciência de que executa uma ação em alguma medida rotinizada, mas na performance a ação adquire um caráter auto-reflexivo. É porque o comportamento restaurado está marcado, enquadrado e separado que ele pode ser articulado em uma performance, de modo chamar atenção para si. Por isso Carlson (2009) caracteriza a performance a partir da atitude: "podemos fazer ações sem pensar, mas quando pensamos sobre elas, isso introduz uma consciência que thes dá a qualidade de performance" (Carlson, 2009: 15).

Nesse sentido, a noção de performance pode aqui nos servir como uma "lente metodológica" que nos permite enxergar certas ações físicas rotinizadas como atividades 
de produção de sentido nos jogos analisados. Em The Beggar o jogar se converte em uma experiência de uma realidade que opera por princípios diferentes daquela em que vivemos, algo que é realçado pela diferença entre o sistema constituído pelos parâmetros e objetivos do jogo e a lógica dos gêneros com os quais ele dialoga. O jogo se coloca contra o jogador no modo como os parâmetros são programados para dificultar gradualmente a realização do objetivo proposto, mas não do mesmo modo como os jogos em geral operam com um aumento gradual do desafio, e sim sob a forma de uma curva exponencial em direção à impossibilidade de vitória. Uma vez que a injustiça do sistema é apresentada sob a forma de uma situação que pode ser vivenciada - ainda que se trate da vivência de uma situação ficcional e estilizada - o resultado não é apenas a constatação das dificuldades enfrentadas por uma pessoa que vive como aquele personagem, mas também a experiência sensível daquela situação, manifesta na frustração e no desespero que acompanham as sessões de jogo.

Entender o jogar como uma performance, é claro, não significa apenas reconhecer que ele provoca emoções ou sensações, mas também perceber que, ao adquirir o caráter auto-reflexivo - ou seja, ao ser acompanhado por um pensamento sobre o próprio jogar - essas emoções e sensações são associadas a obra como o sentido dela, como um efeito estético produzido a partir da estruturação planejada da experiência. A experiência estética não consiste apenas em sentir a emoção, mas em reconhecer que essa emoção foi comunicada pela obra, que foi fruto da operação poética do artista e que pode ser compartilhada por outros que experimentem a obra.

Para Dewey, nós reagimos às percepções sensoriais "com valores afetivos, criativos e intelectuais extraídos de nós mesmos" (Dewey, 2010: 242). Nesse sentido, não apenas a construção do sentido se dá através do resgate de experiências passadas, como também a excitação afetiva. Quando Grey constrói sua narrativa do modo como o faz, conduzindo o jogador a acionar seu repertório de experiências (não só as narrativas, como também as pessoais), cria um canal pelo qual a reviravolta que converte o jogo em uma narrativa sobre perda pode encontrar eco na experiência do jogador. Uma vez que a perda de um ente querido é uma experiência praticamente universal, o jogo encontra ressonância direta com a carga de experiências dos jogadores, resultando em descrições apaixonadas como a do(a) usuário(a) "Jonny_S", feita na seção de comentários da página sobre o jogo:

Logo de cara eu podia ver que a garota não estava apenas sentada ali, mas perdida em pensamento. Uma vez que o personagem que você controla estava ativo e se movendo, eu podia ver que não era o mundo dele que era cinza, mas o dela. O primeiro item que encontrei foi o que estava perto do túmulo (a flor amarela), o que me disse que o personagem com o qual eu jogava estava morto, explicando assim o mundo cinzento dela. Eu não vejo a coisa como jogar como um fantasma, no entanto, e sim como enxergar o mundo através dos olhos dela.

A princípio, ela só consegue pensar nele. Tudo o mais é duro e imóvel, mas ele ainda é tão real. Gradualmente, no entanto, faíscas de cor 
retornam conforme ela percebe que ainda há alegria. Ele desaparece da sua mente, lentamente, enquanto outras coisas começam a entrar em foco. Ao final, ele dispersa em tudo ao redor dela, porque mesmo que ela não esteja mais dominada pelo pesar, tudo o que ela vê carrega um traço dele. Ela nunca mais poderia olhar para um lago azul sem pensar naquele colar que ele lhe deu, ou ver um pôr-do-sol alaranjado sem lembrar-se do ursinho que ele tinha.

Esse jogo captura de maneira incrível, para mim, a sensação de perder alguém que você ama, seguir em frente, e ainda assim nunca vê-los verdadeiramente partir. ${ }^{3}$

A leitura feita por "Jonny_S” só é possível graças ao modo como o jogo engaja elementos do repertório na produção do sentido, com destaque para o papel de um repertório pessoal nesse processo. O resultado é uma carga direta de emoção que não decorre apenas das sensações provocadas pela mecânica ou narrativa do jogo, mas sim evocadas de experiências passadas e aderidas a esses elementos. Desse modo, emoção e sentido emergem como indissociáveis um do outro no interior do efeito produzido pelo jogo. Small Worlds opera por uma lógica similar, associando o sentido da obra à nostalgia em relação aos jogos que homenageia, ao evocar as sensações produzidas por esses jogos antigos e seus gráficos pixelizados.

Outra obra que depende das emoções e sensações provocadas por jogos antigos é Dys4ia, um jogo autobiográfico criado pela transexual Anna Anthropy, onde ela relata a sua experiência pessoal com a terapia hormonal. O título do jogo faz referência à disforia de gênero, outro nome dado à noção controversa de transtorno de identidade de gênero.

Dys4ia é dividido em quatro capítulos ou "níveis", cada um deles constituído por um relato que combina texto e pequenos jogos relacionados a questões que a autora discute. Uma vez que o fio condutor da obra é o relato verbal, a obra poderia ser classificada como um caso de "narrativa interativa" com elementos secundários típicos do video game. Entretanto, esses elementos desempenham um papel crucial na produção de sentido através da obra, mesmo que a sua definição como um game possa ser questionada.

Em Dys4ia, a autora narra a sua experiência através de frases curtas, que são acompanhadas de mini-games - pequenas peças interativas igualmente curtas e simples, que evocam sentidos e sensações a partir da mecânica e do diálogo com mecânicas de jogo clássicas. A obra começa com a frase "Me sinto estranha a respeito do meu corpo". Ao mesmo tempo, o jogador assume o controle de um avatar anguloso e abstrato, cuja forma remete tanto às primeiras figuras humanas representadas nos jogos pioneiros de arcade quanto a uma peça do jogo Tetris (Figura 9). O cenário, uma espécie de muro de tijolos com um espaço no qual a peça poderia ser encaixada, evoca também a mecânica de Tetris, segundo a qual é preciso encaixar cada nova peça no espaço disponível sem deixar vãos. No caso desse mini-game, o jogador percebe o que precisa fazer a partir da referência ao jogo clássico, mas logo vê que é impossível encaixar a peça no espaço

\footnotetext{
3 Tradução livre dos autores.
} 
disponível, resultado que reforça o sentido da frase inicial. Em Dys4ia, a autora usa de elementos familiares (as mecânicas de jogo) como metáfora para a situação da protagonista, fazendo com que o sentimento evocado pelos mini-games se associe às situações descritas. Uma vez que a obra trata de uma experiência que não é familiar a grande parte do público - certamente ela não é um tema narrativo recorrente, especialmente nos games -, a combinação entre relato verbal e mecânicas familiares de jogo resulta em empatia, uma vez que o jogador se identifica com os jogos referenciados e relaciona as sensações evocadas com a experiência narrada, mesmo que não se identifique diretamente com a experiência.

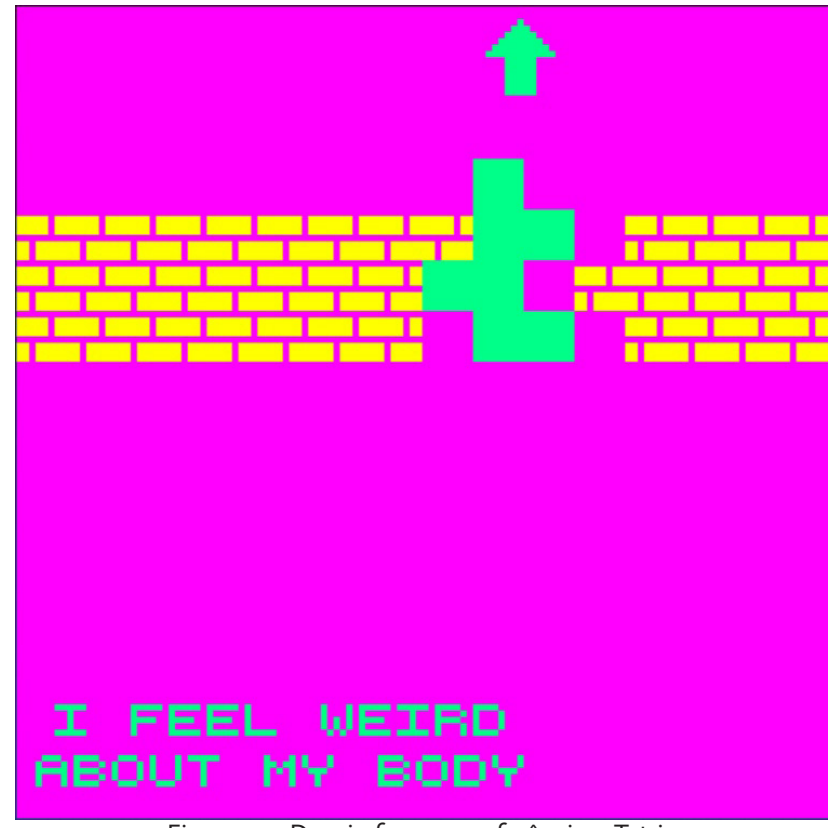

Figura 9 - Dys4ia faz uma referência a Tetris

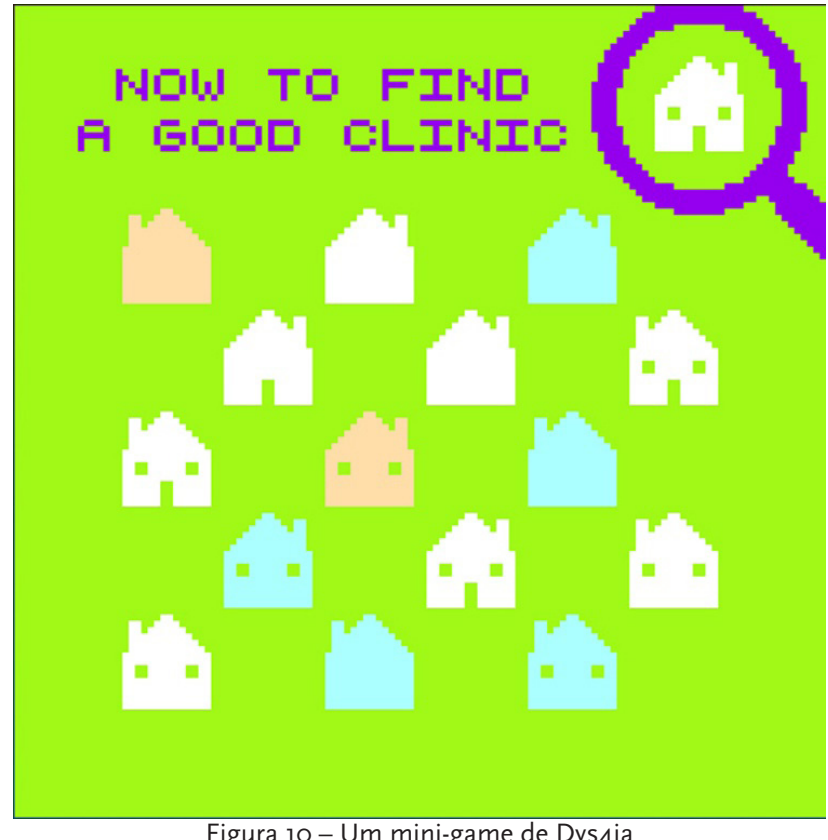

Figura 10 - Um mini-game de Dys4ia 
Há diversas mecânicas diferentes entre os mini-games que compõem a obra. Em muitas delas, como no caso do bloco que não encaixa, o sentido é produzido a partir da frustração do objetivo proposto, como no mini-game em que o jogador tenta ajudar a personagem a se vestir, enquanto que o letreiro explica que "roupas femininas não cabem". Em outras, como naquela em que o jogador deve ajudá-la a encontrar uma clínica que atenda a suas expectativas (Figura 10), a mecânica serve para realçar a dificuldade e os obstáculos enfrentados pela autora.

Vários dos mini-games dialogam entre si, ou são retomados em diferentes "níveis" do jogo com novos significados. É o caso daquele acompanhado pelo letreiro que informa que "essas feministas não me aceitam como mulher": aqui o jogador controla um ícone em forma de escudo; "bocas" femininas estilizadas disparam balões de diálogo contendo o símbolo de Marte, identificado com o gênero masculino, e o jogador deve rebater esses "ataques" como uma raquete rebatendo a bola, em referência clara ao jogo Pong. Mais tarde, a mesma mecânica é retomada em uma cena que diz: "Tudo o que minha namorada diz me faz chorar". Mas aqui o balão de diálogo contém um ponto de interrogação, e ao invés de refletir o projétil de volta, o escudo pisca ao ser atingido (uma convenção do video game que denota dano sofrido).

O "quebra-cabeça" inicial é uma das cenas recorrentes. No nível 3, durante o tratamento hormonal, a mesma mecânica reaparece com o letreiro "me sinto mais estranha a respeito do meu corpo do que jamais senti", e o bloco que representa a percepção da protagonista a respeito do próprio corpo parece ainda mais disforme em relação ao espaço no qual deveria caber. Ao fim do jogo, no entanto, o mini-game retorna, mas não há letreiro: apenas o bloco, agora alternando rapidamente entre diferentes configurações, sem jamais caber no espaço. A cena serve como uma bela conclusão para a narrativa: o corpo de Anna provavelmente jamais irá atender as expectativas geradas pela percepção social de gênero, mas devido ao aumento da sua auto-estima e confiança, trazido pelo tratamento e relatado em cenas anteriores, ela já não se sente "estranha".

É importante reconhecer que, na experiência estética, não se trata apenas de conferir emoção à experiência da obra a partir do repertório, e sim de uma relação de duas vias na qual a nova experiência também questiona a validade de regras e convenções estabelecidas. É a reorganização mútua descrita por Iser, onde as experiências passadas são evocadas para dar forma à experiência estética (dão corpo e sugestividade à experiência, nos termos de Dewey), mas também são alteradas pelas relações estabelecidas com os elementos da obra.

À guisa de encerramento, devemos destacar que, nos exemplos discutidos, procuramos demonstrar um caminho analítico alternativo ao dos narratólogos, que tendem a descrever o video game através da metáfora do texto como mundo. Na articulação teórica que apresentamos, evidencia-se outra abordagem — na qual a noção de virtual relaciona-se ao "potencial", e não ao "ficcional" — a do texto como jogo. Essa metáfora está no cerne de teorias como a de Iser, que concebem o texto como um objeto incompleto que precisa ser atualizado pelo leitor. 
Devemos, é claro, entender essas expressões pelo que elas são - metáforas - e manuseá-las de acordo: a relação entre os termos "texto" e "jogo", por exemplo, pode variar entre relação literal (o texto é jogo nos romances de mistério, onde há um quebra-cabeça a ser resolvido) e uma relação vaga (onde o conceito é reduzido à sua essência: uma atividade governada por regras e exercida por prazer). O que há de comum a todas as aplicações da metáfora do jogo parece ser a noção de que a leitura deve ser reconhecida como uma relação interativa e de caráter auto-reflexivo com os signos que compõem o texto.

Apesar de nos distanciar dos narratólogos, essa opção analítica não nos aproxima da corrente de pensamento tradicionalmente oposta a esta, a dos ludólogos — pois estes optam somente pela aplicação literal do conceito de jogo e recusariam o uso da metáfora do texto. Além disso, aqueles que utilizam o texto como conceito o fazem de modo mais literal do que nós: quando Aarseth diz entender o ciberleitor como uma figura "mais integrada" no texto do que o leitor tradicional, na verdade apenas admite uma sobrevalorização das possibilidades de atuação física do primeiro - explorar, se perder, descobrir caminhos secretos - em relação à atuação mental do segundo, que realiza essas "ações" apenas metaforicamente. Aarseth provavelmente criticaria a nossa falta de precisão formal e veria uma espécie de imperialismo teórico na adesão a teorias que não foram originalmente formuladas tendo em mente as diferenças introduzidas pelo suporte digital, mas a sua abordagem descritiva da organização mecânica do texto, ao tratá-lo como objeto e não como evento ou experiência, seria vista à luz das formulações de Iser e Dewey como incapaz de explicar como se dá a produção de sentido e de efeitos estéticos.

Conforme os exemplos analisados nos mostram, estamos lidando aqui com dois níveis de metáforas: games que são textos que são jogos. Isso quer dizer que nem todo game poderá ser descrito como um "texto que é um jogo", embora se possa dizer que há uma afinidade potencial entre os jogos e a experiência estética tal como descrita por Iser e Dewey. Ainda assim, investigar o meio pela metáfora do texto como jogo e a noção de performance permite superar alguns dos principais obstáculos colocados diante do reconhecimento do video game como arte ao demonstrar que, ao contrário do que muito se diz, ser um jogo não é obstáculo à experiência estética.

\section{REFERÊNCIAS}

Aarseth, E. (1997) Cybertext: Perspectives on Ergodic Literature, Baltimore: The John Hopkins Press.

Carlson, M. (2010) Performance: Uma Introdução Crítica, Belo Horizonte: Editora UFMG.

Castañares, W. (2007) “Cultura Visual y Crisisde laexperiência”, CIC Cuadernos de Información y Comunicación, 12 (1). disponível em http://revistas.ucm.es/index.php/CIYC/article/view/CIYCo707110029A, consultado em $08 / 10 / 2011$.

Dewey, J. (2010) Arte como Experiência, São Paulo: Martins Fontes.

Iser, W. (1994) The Act of Reading: A Theory of Aesthetic Response, Baltimore: The John Hopkins Press.

Murray, J. (2003) Hamlet no Holodeck: O Futuro da Narrativa no Ciberespaço, São Paulo: Itaú Cultural, Unesp. 
Pareyson, L. (1997) Os Problemas da Estética, São Paulo: Martins Fontes.

Ryan, M-L. (2001) Narrative as Virtual Reality.Immersion and interactivity in Literature and Electronic Media, Baltimore: The John Hopkins University Press.

Schechner, R. (2006) “What is Performance?", in Schechner, R. (2006) Performance Studies: An Introduction, New York \& London: Routledge, pp. 28-51.

Tatarkiewicz, W. (1997) Historia de Seis Ideas. Arte, Belleza, Forma, Creatividad, Mimesis, Experiencia Estética, Madrid: Tecnos.

\section{LUDOGRAFIA}

Alexey Pajitnov (1984), Tetris $®$

Armor Games (2011), Grey

David Shute (2009), Small Worlds

Newgrounds (2012), Dys4ia

Nintendo (1981), Donkey Kong®

Scott Brodie (2009), The Beggar

\section{NOTAS BIOGRÁFICAS}

Carlos Magno Camargos Mendonça - Professor do Programa de Pós-Graduação em Comunicação (PPGCOM) da Faculdade de Filosofia e Ciências Humanas - Fafich/ UFMG (Belo Horizonte, Brasil)

E-mail: macomendonca@gmail.com

Faculdade de Filosofia e Ciências Humanas - Fafich/UFMG, Av. Antônio Carlos, 6627 - Campus Pampulha - CEP: 31270-901 - Belo Horizonte, MG -Brasil

Filipe Alves de Freitas - Doutorando pelo Programa de Pós-Graduação em Comunicação (PPGCOM) da Faculdade de Filosofia e Ciências Humanas - Fafich/UFMG (Belo Horizonte, Brasil)

E-mail: filipealvesdefreitas@gmail.com

Faculdade de Filosofia e Ciências Humanas - Fafich/UFMG, Av. Antônio Carlos, 6627 - Campus Pampulha - CEP: 31270-901 - Belo Horizonte, MG -Brasil

* Submetido: 30-11-2014

* Aceite: 15-3-2015 